\title{
Proctocolitis in breast fed infants: a contribution to differential diagnosis of haematochezia in early childhood
}

\author{
W Pumberger, G Pomberger, W Geissler
}

\begin{abstract}
Dietary protein induced proctocolitis in exclusively breast fed infants is rarely taken into consideration as a cause of rectal bleeding or blood streaked stool in the neonatal period and early infancy. Eleven babies are presented in whom it is believed that bleeding through the rectum was due to proctocolitis as a result of allergy triggered by cows' milk protein transferred to the infants via the breast milk. Colonoscopy was performed in five infants, revealing benign eosinophilic proctocolitis. Standard treatment was the exclusion of the allergen from the mother's diet. Resolution of visible rectal bleeding took place within 72 to 96 hours after elimination of the offending protein from the mother's diet.

(Postgrad Med f 2001;77:252-254)
\end{abstract}

Keywords: haematochezia; benign eosinophilic infantile proctocolitis; breast fed infants; cows' milk allergy

Dietary protein induced eosinophilic proctocolitis in exclusively breast fed infants is rarely taken into consideration as a cause of rectal bleeding in the neonatal period or early infancy. Failure to appreciate this entity may lead to inappropriate diagnostic or therapeutic intervention. The aim of our presentation is to describe clinical signs and symptoms, diagnosis, and treatment of this condition, which is proving to be of increasing importance in neonates and infants.

Methods and results (see table 1)

During a period of 18 months 11 babies were admitted to our department because of rectal bleeding or blood streaked stool. All 11 children (six boys and five girls) were born at term and were exclusively breast fed up to the time of our initial evaluation. The mean age at the onset of symptoms was 7.5 weeks (range 5-10 weeks) and referral for evaluation oc- curred from the first to the third week after onset. Predominant signs and symptoms were repeated mild rectal bleeding, blood streaked bowel movements, and mucous blood mixed with stool.

Physical examination showed all babies apparently well, thus serious conditions could be ruled out. No anal fissures or perianal dermatitis were found to account for the bleeding. Four children presented with colicky pain and abdominal distension. In only one case was there a possible family history of cows' milk allergy and a known history of atopy.

Serum haemoglobin was shown to be below the normal range in two infants and investigation of serum albumin in seven infants yielded hypoalbuminaemia in one child. Three children demonstrated peripheral eosinophilia (range $8 \%-24 \%$ ). Stool cultures were negative for routine pathogens including ova and parasites.

In five children rectocolonoscopy up to the splenic flexure was performed under general anaesthesia, showing macroscopic evidence of colitis (patchy focal or diffuse mucosal oedema and erythema, friability of the mucosa and small erosions). Involvement of the rectosigmoid was universal, whereas extension into the descending colon was limited. In four infants inflammatory lesions appeared together with nodular lymphoid hyperplasia ("goose pimply appearance"; fig 1). Histological examination of biopsy specimens revealed colitis with hyperaemia and predominance of eosinophils in the epithelium, lamina propria, and submucosa.

In the next six babies with the identical clinical signs and symptoms, invasive examination was not carried out under the assumption of

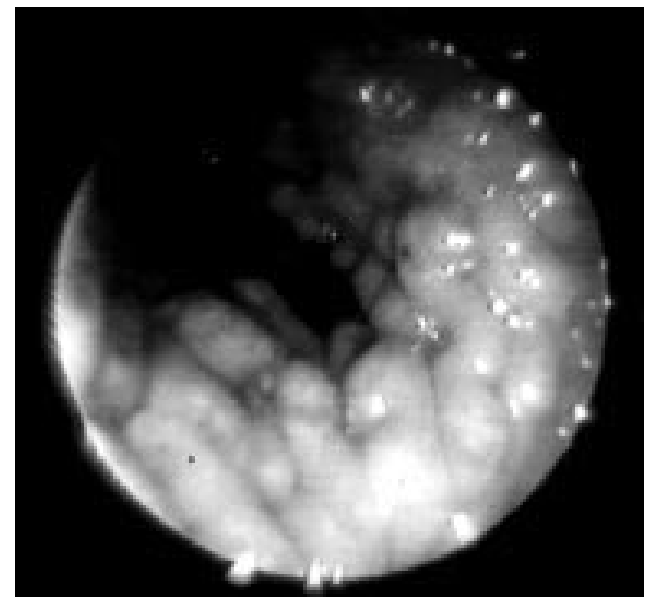

Figure 1 Endoscopic aspect of lymphonodular hyperplasia of the colon showing multiple 1-4 $\mathrm{mm}$ nodules of the colon ("goose pimply appearance").
Rectocolonoscopy

Lymphonodular hyperplasia

7.5 weeks $(5-10$ weeks)
$4 / 11$
$9 / 11$
$2 / 11$
$11 / 11$
$4 / 11$
$0 / 11$
$2 / 11$
$1 / 7$
$2 / 11$
$3 / 11$
$5 / 11$
$5 / 5$
$4 / 5$




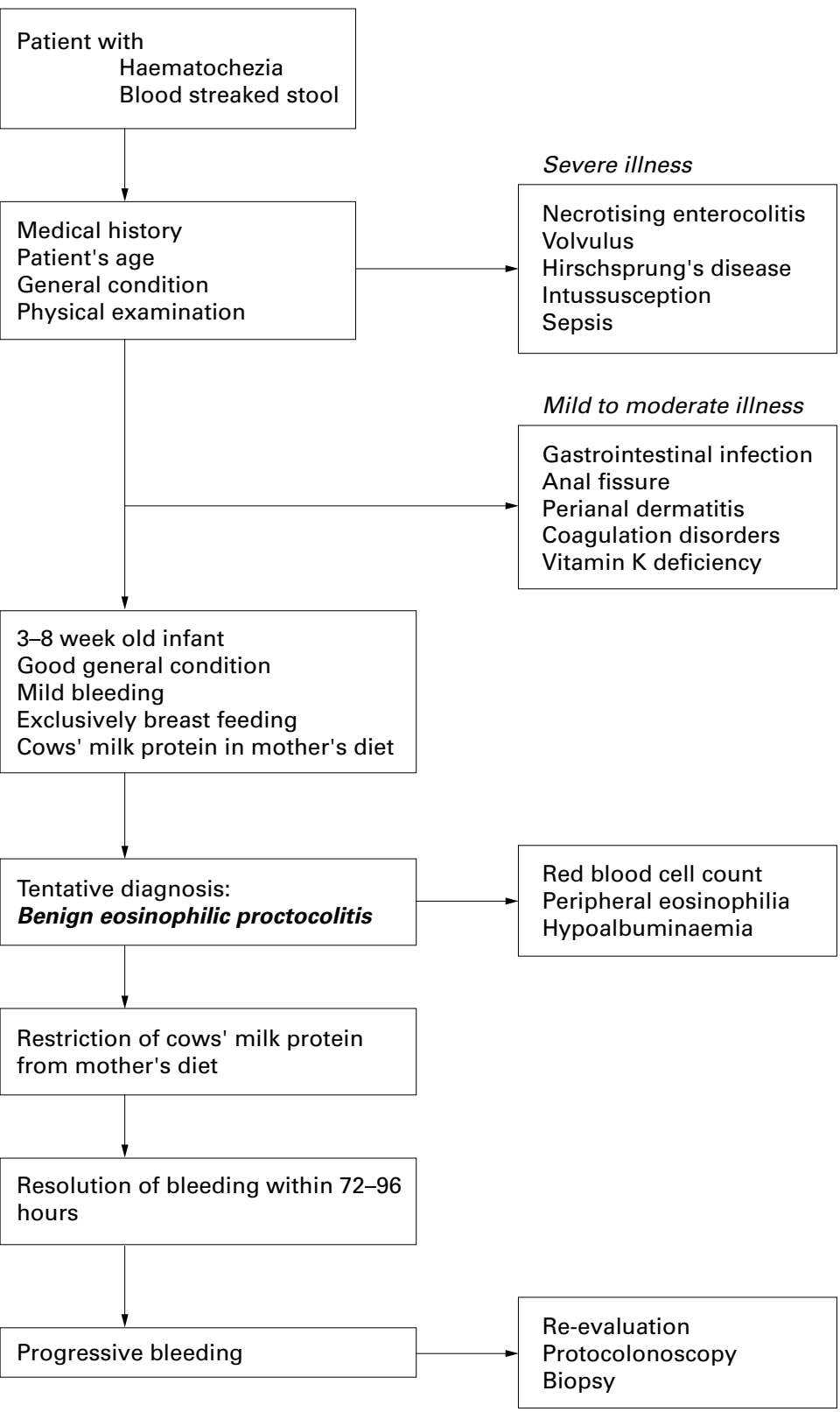

Figure 2 Algorithm in diagnosis and treatment of haematochezia and blood streaked stool in early infancy.

\section{Learning points}

- A useable management algorithm should provide the practitioner with a better appraisal of unexplained rectal bleeding in the neonatal period and early infancy.

- Dietary protein induced eosinophilic proctocolitis in apparently exclusively breast fed infants has been less emphasised.

- In the case of strong evidence for allergic colitis we suggest deferring further invasive investigation.

- Strict exclusion of cows' milk products is recommended and will result in resolution of haematochezia.

better appraisal of unexplained rectal bleeding in infants. ${ }^{23}$ It is important to determine when a case of rectal bleeding should be aggressively evaluated (for example, volvulus, necrotising enterocolitis, intussusception). If the episode of the bleeding has been mild or self limiting, it is reasonable to defer extensive investigation (fig 2). ${ }^{3}$

Although allergic proctocolitis due to cows' milk or soy protein is a significant cause of rectal bleeding in infants, dietary protein induced proctocolitis in exclusively breast fed infants has been less emphasised. ${ }^{4-6}$ A concept of a classical type IV hypersensitivity reaction at the level of the colonic mucosa is disputed, although the exact responsible mechanisms remain unknown. ${ }^{78}$ Proteins in the maternal diet have been recovered in breast milk and may act as an allergen. ${ }^{9}$

A presumptive diagnosis of proctocolitis can be established on the ground of a precise case history. Onset occurs in the first four months of life (range 1 week to 5 months), and apart from the bleeding the exclusively breast fed infants are apparently well. Mild-to-moderate diarrhoea or grossly blood streaked stool with mucus are the consistent features. No anal fissures or perianal dermatitis are found to account for the bleeding. Signs and symptoms of malabsorption, abdominal distension, severe diarrhoea, vomiting or impaired growth, which would indicate food allergy, are absent. ${ }^{4}$ Features of type I hypersensitivity such as anaphylaxis and rash are lacking. Infectious origin can be excluded by stool tests including ova parasites.

Peripheral eosinophilia, raised serum IgE concentration, a positive family history of allergy, and positive skin sensitivity tests may be present, but are not pathognomonic.

In ignorance of the true nature of the disease, colonoscopy will be performed in many infants. Endoscopy demonstrates patchy focal or diffuse mucosal oedema and erythema of various distribution and severity, mucosal friability, haemorrhagic suffusion, and small erosions. ${ }^{58}$ The sigmoid colon and rectum are predominantly involved, whereas extension of the disease into the descending colon is less common. The colon proximal to the splenic flexure is always excluded. The same limitation 
of the inflammation to the sigmoid and descending colon has been reported in both cows' milk protein and soy protein induced enteritis. ${ }^{710} \mathrm{Up}$ to $40 \%$ of infants additionally demonstrate lymphoid nodular hyperplasia with multiple, distinct and raised $1-4 \mathrm{~mm}$ nodules uniformly distributed over the colonic mucosa ("goose pimply appearance"; fig 1). ${ }^{11}$

Histological examination shows the uniform feature of distinct eosinophilic and plasma cell infiltration of the epithelium, lamina propria, and submucosa. ${ }^{6712}$ The regular structure of the mucosa is preserved, but all specimens showed a striking hyperaemia. ${ }^{56}$

In the case of proved or suggested allergic proctocolitis we recommend strict exclusion of cows' milk products from the mother's diet. It is important to emphasise that the presence of allergic colitis caused by cows' milk proteins should not raise concern about breast feeding. Resolution of the visible rectal bleeding takes place within 72 to 96 hours after elimination of the offending protein. ${ }^{67}$ Resolution has also been observed when a casein-hydrolysate based formula is substituted for cows' milk. In singular cases, soy protein, corn, egg, and chocolate may cause a similar reaction as the sole allergen or coincidentally with cows' milk. ${ }^{7}$

Most infants experience a very benign course of the disease, and in some series up to $20 \%$ of infants had gradual spontaneous resolution of the bleeding without changes in the mother's diet. This fact suggests that the condition might be self limiting. ${ }^{6710} \mathrm{Up}$ until now no long term risk of development of an allergic disease or chronic intestinal inflamma- tory disease has been reported and all children tolerated introduction of the offending protein by 1 year of age. ${ }^{4}$

The condition appears to be common enough that practitioners should take it into account as a distinct clinical syndrome in apparently well neonates and infants with bleeding through the rectum. In the case of strong evidence for allergic colitis we suggest deferring further invasive investigation. Further evaluation is recommended only if use of the algorithm of diagnosis and treatment (fig 2) does not result in resolution of rectal bleeding.

1 Vinton NE. Gastrointestinal bleeding in infancy and childhood. Gastroenterol Clin North Am 1994;23:93-121.

2 Silber GH, Klish WJ. Hematochezia in infants less than 6 months of age. Am f Dis Child 1986;140:1097-8.

3 Raine PAM. Investigation of rectal bleeding. Arch Dis Child 1991;66:279-80

4 Lake AM, Whitington PF, Hamilton SR. Dietary proteininduced colitis in breast-fed infants. F Pediatr 1982;101:90610.

5 Odze RD, Bines J, Leichtner AM, et al. Allergic proctocolitis in infants: a prospective clinicopathologic biopsy study. Hum Pathol 1993;24:668-74.

6 Anvenden-Hertzberg L, Finkel Y, Sandstedt B, et al. Proctocolitis in exclusively breast-fed infants. Eur $\mathcal{F}$ Pediatr 1996;155:464-7.

7 Machida HM, Catto-Smith AG, Gall DG, et al. Allergic colitis in infancy: clinical and pathological aspects. $\mathcal{F}$ Pediatr Gastroenterol Nutr 1994;19:22-6.

8 Thomas DW, Talley NJ, Mahnovski V, et al. Rectal mucosal major basic protein in infants with dietary protein-induced colitis. Ann Allergy 1993;71:66-9.

9 Powell G. Milk- and soy-induced enterocolitis in infancy. $\mathcal{F}$ Pediatr 1978;93:553-60.

10 Dupont C, Badual J, Le Luyer B, et al. Rectosigmoidoscopic Dupont C, Badual J, Le Luyer B, et al. Rectosigmoidoscopic
findings during isolated rectal bleeding in the neonate. $f$ Pediatr Gastroenterol Nutr 1987;6:257-64.

11 Gottrand F, Erkan T, Farriaux JP, et al. Food-induced bleeding from lymphonodular hyperplasia of the colon. Am f Dis Child 1993;147:821-3.

12 Lake AM. The polymorph in red is no lady. $\mathcal{F}$ Pediatr Gastroenterol Nutr 1994;19:4-6.

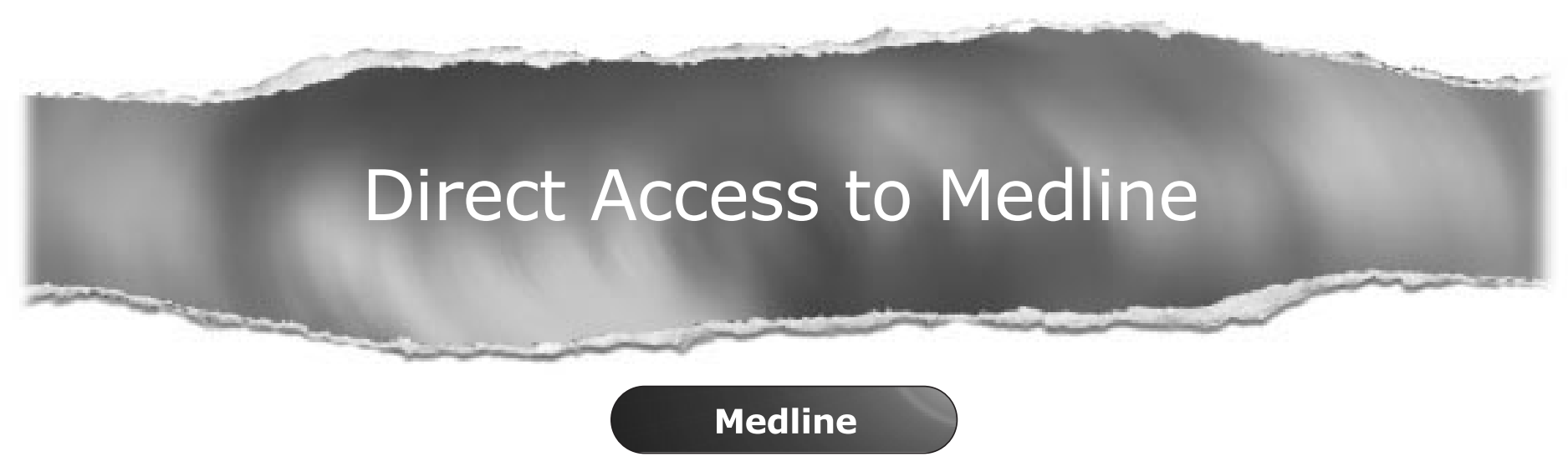

Link to Medline from the homepage and get straight into the National Library of Medicine's premier bibliographic database. Medline allows you to search across 9 million records of bibliographic citations and author abstracts from approximately 3,900 current biomedical journals.

www.postgradmedj.com 